\title{
O QUE DIZEM GRADUANDOS EM PEDAGOGIA SOBRE SUAS PRÁTICAS DE LEITURA: O OLHAR DOS LETRAMENTOS ACADÊMICOS ${ }^{1}$
}

\section{WHAT DO UNDERGRADUATES IN PEDAGOGY SAY ABOUT THEIR READING PRACTICES: THE LOOK ACADEMIC LITERACIES}

Elizabeth Maria da Silva*

\begin{abstract}
Resumo: Neste artigo, apresenta-se um estudo de caso sobre práticas de leitura acadêmica. Objetiva-se examinar como estudantes do curso de Pedagogia, de uma universidade federal brasileira, descrevem e analisam suas experiências com a leitura de textos acadêmicos, resgatadas, retrospectivamente, em entrevistas semi-estruturadas. Fundamentada na perspectiva dos Letramentos Acadêmicos (LEA; STREET, 1998), a partir de uma abordagem qualitativa (BOGDAN; BIKLEN, 1994), a análise mostra estranhamentos e dúvidas dos estudantes quanto aos modos pelos quais a leitura acontece na universidade. As dificuldades em significar as práticas de leitura acadêmica podem estar vinculadas a uma prática institucional do mistério (LILLIS, 1999) e ao modelo de letramento autônomo (STREET, 1984).
\end{abstract}

Palavras-chave: Contextos Acadêmicos. Letramentos Acadêmicos. Leitura. Prática institucional do mistério.

\begin{abstract}
In this article, a case study on academic reading practices is presented. It aims to examine how students of the Pedagogy course of a Brazilian federal university describe and analyze their experiences with the reading of academic texts, recovered retrospectively, in semi-structured interviews. Based on the perspective of Academic Literacies (LEA; STREET, 1998), from a qualitative approach (BOGDAN; BIKLEN, 1994), the analysis shows students' strangeness and doubts about the ways in which reading happens at university. The difficulties in signifying academic reading practices may be linked to an institutional practice of the mystery (LILLIS, 1999) and to the autonomous literacy model (STREET, 1984).
\end{abstract}

Keywords: Academic Contexts. Academic Literacies. Reading. Institucional Practice of Mystery.

\section{Introdução}

Há aproximadamente duas décadas, os pesquisadores britânicos Mary Lea e Brian Street publicaram um artigo seminal Student writing in higher education: an academic literacies approach, fruto de uma pesquisa que desenvolveram sobre o ensino de escrita acadêmica, em universidades do Reino Unido. Nessa investigação, identificaram três abordagens por meio das quais a escrita era focalizada: Habilidades de Estudo, Socialização Acadêmica e Letramentos Acadêmicos (LEA; STREET, 1998). Essa última é defendida por eles, visto focalizar a leitura e a escrita enquanto práticas

\footnotetext{
${ }^{1}$ Neste artigo, apresento dados explorados em minha tese de doutorado intitulada Um estudo de caso da escolarização de textos lidos e produzidos em contexto acadêmico,orientada pela Profa Dra Maria Lúcia Castanheira.

* Mestre em Linguagem e Ensino pela Universidade Federal de Campina Grande (UFCG) e doutora em Educação pela Universidade Federal de Minas Gerais (UFMG). Professora da Unidade Acadêmica de Letras, da UFCG, onde atua tanto na graduação quanto no Programa de Pós-Graduação em Linguagem e Ensino (PPGLE/UFCG). Membro do Grupo de Pesquisa Teorias da Linguagem e Ensino (UFCG). Email: professoraelizabethsilva@gmail.com.
} 
sociais e situadas que variam de acordo com as áreas e disciplinas em que são requeridas, assim como entre os diferentes contextos institucionais em um mesmo país (CASTANHEIRA; STREET; CARVALHO, 2015) ou em diferentes países (ROBINSON-PANT; STREET, 2012).

A abordagem dos Letramentos Acadêmicos tem norteado inclusive o desenvolvimento de algumas pesquisas brasileiras, a exemplo de Marinho (2010), Fiad $(2011,2013,2016)$ e Fischer $(2010,2011)$. No entanto, na maioria delas, privilegiam-se as práticas de escrita, como objeto de estudo, em detrimento das práticas de leitura, também constitutivas do conceito de letramentos (STREET, 2003).

A escassez de estudos sobre leitura acadêmica, ancorados na abordagem dos Letramentos Acadêmicos, é percebida não apenas no contexto brasileiro, mas também em contexto internacional. Pesquisadoras como Paula Carlino e Graciela Fernández, da Universidad de Buenos Aires, e Ursula Wingate, do King's College, têm defendido a necessidade de investigar a leitura acadêmica, bem como de ensiná-la aos universitários (FERNÁNDEZ; CARLINO, 2010; WINGATE, 2015).

Soma-se ao reconhecimento dessa lacuna na área o interesse em conhecer experiências de estudantes do nível superior com a leitura de textos acadêmicos, visto que, pelo fato de estarem ingressando em uma nova comunidade disciplinar (WINGATE, 2015), é provável que eles não conheçam as práticas de leitura, mas também de escrita e de oralidade, que são construídas nesse espaço. Como se trata de uma hipótese, é necessário investigar o que os próprios universitários têm a dizer sobre suas experiências com esse tipo de leitura. Assim sendo e com vistas à delimitação do espaço de pesquisa e dos seus participantes, aproveitei a minha condição de doutoranda, em uma universidade brasileira, para desenvolver essa pesquisa em tal instituição, particularmente nos cursos de Pedagogia e Psicologia, em virtude de laços colaborativos que foram estabelecidos.

Ante a esse cenário e considerando os limites do presente artigo, a pergunta que busco responder neste texto é: Quais os significados das práticas de leitura acadêmica, no curso de Pedagogia, ofertado em uma universidade brasileira, considerando entrevistas realizadas com estudantes vinculados a esse curso? Já o objetivo principal desse estudo é examinar como esses estudantes descrevem e analisam suas experiências com a leitura de textos acadêmicos, desfrutadas no curso referido.

Uma vez atendendo a esse objetivo, espero contribuir para as discussões sobre questões teóricas e aplicadas que envolvem as práticas de leitura em contexto universitário, exploradas à luz da abordagem dos Letramentos Acadêmicos, a partir dos significados que lhes são atribuídos por aqueles que vivenciam o processo de inserção e integração em uma nova comunidade disciplinar, os próprios graduandos.

Informo que organizei o presente artigo em três seções, excetuando esta introdução e as referências. Na primeira, situo brevemente natureza da pesquisa, fonte de dados, participantes e procedimentos analíticos. Na segunda, subdividida em duas, eu apresento, respectivamente, os conceitos norteadores do estudo e as experiências de leitura acadêmica dos participantes, à luz desses conceitos. Na terceira, e última seção, sinalizo algumas implicações dos resultados alcançados.

\section{Metodologia}

A pesquisa foi desenvolvida a partir da abordagem qualitativa. Com base nessa abordagem, em que são enfatizados "a descrição, a indução, a teoria fundamentada e o 
estudo das percepções pessoais" (BOGDAN; BIKLEN, 1994, p. 11), busquei explorar o que os participantes do estudo diziam sobre suas experiências com a leitura acadêmica e os modos pelos quais eles as significavam. Sem julgá-los, sem generalizar suas falas, tentei evidenciar suas relações com as práticas de leitura acadêmica e os significados por eles construídos nessas relações, conforme esperado inclusive nos estudos fundamentados na abordagem dos Letramentos Acadêmicos, a exemplo do que estamos relatando.

Trata-se de um estudo de caso (MITCHELL, 1984) realizado com quatro estudantes calouros e oito concluintes do curso de Pedagogia ofertado em uma universidade federal brasileira, contatados via e-mail. Mediante a autorização do Comitê de Ética em Pesquisa (CAAE 39898414.4.0000.5149), entrevistei esses participantes, individualmente, entre quarenta a sessenta minutos, no próprio campus da instituição focalizada. Fiz três entrevistas semi-estruturadas com cada um dos calouros e duas com cada concluinte.

Planejei tais entrevistas com base nas contribuições de Patai (1988) que defende um olhar sensível para com os entrevistados - ouvi-los, sem julgá-los; suspender os nossos conhecimentos, valores e crenças a fim de ouvir e aprender com os conhecimentos, valores e crenças do outro. Recorri também às sugestões dadas por Spradley (1979) que, à semelhança de Patai (1988), defende que a relação entre entrevistador e entrevistado seja marcada por um processo de humanização, em que aquele se coloca aberto para conhecer e, sobretudo, aprender com este. Segundo ele, o pesquisador "precisa fazer questões, ouvir em vez de falar, exercer papel passivo e não assertivo, expressar interesse verbal na outra pessoa e mostrar interesse pelo contato do olho e outros significados não verbais" (SPRADLEY, 1979, p. 46) ${ }^{2}$.

Ao transcrevê-las, adotei alguns símbolos sugeridos por Marcuschi (1991) para representar os elementos da conversação, fazendo algumas adaptações nas falas transcritas. Adaptei para a escrita a pronúncia dos fonemas $/ e /$ e $/ o /$ como $/ i / \mathrm{e} / u /$, respectivamente. Então, quando os participantes pronunciavam, por exemplo, gostu, num sei, di, eu os adaptava para gosto, não sei, de, respectivamente. Adaptei também a abreviação de palavras: substituí, por exemplo, tou, tá, tava, por, respectivamente, estou, está, estava. Como a minha pesquisa não estava direcionada ao estudo da variação linguística, as adaptações feitas não interferiram no alcance do meu objetivo, pelo contrário, deverão contribuir para uma fluidez na leitura dos trechos transcritos.

Por fim, informo que, para o processo analítico das entrevistas, adotei dois conceitos que me auxiliaram na definição dos aspectos que tomaria como base na análise das falas dos participantes, a saber: pistas de contextualização (GUMPERZ, 2002 [1982]) e escolhas discursivas (IVANIC, 1994).

\section{Práticas de leitura à luz dos Letramentos Acadêmicos}

\subsection{Conceitos basilares}

\footnotetext{
2 Texto original: "asking questions, listening instead of talking, talking a passive rather than an assertive role, expressing verbal interest in the other person, and showing interesse by eye contact and other nonverbal means."
} 
Para explorar as práticas de leitura dos participantes da pesquisa relatada, adoto como referencial teórico a perspectiva dos letramentos proposta pelo grupo dos Novos Estudos do Letramento (NEL) (STREET, 1993, 2003; GEE, 1996 [1990]), bem como a abordagem dos Letramentos Acadêmicos (LEA; STREET, 1998).

$\mathrm{Na}$ perspectiva dos NEL, a leitura (e a escrita) são concebidas como práticas sociais e situadas, em consonância com o conceito de modelo de letramento ideológico construído por Street (1984). Nessa perspectiva, interessa ao pesquisador observar as formas pelas quais as pessoas se inserem nas práticas de leitura e de escrita presentes em diferentes contextos, os modos pelos quais elas lidam com tais práticas situadas e os significados específicos que lhes atribuem. A leitura não é vista como descontextualizada, universal, autônoma, como o é no modelo de letramento autônomo (STREET, 1984). Pelo contrário, é considerada socialmente situada e dependente dos diversos contextos em que se configura enquanto prática.

Embora Street (1984) tenha estabelecido a diferenciação entre os modelos autônomo e ideológico, ele mesmo, em publicações posteriores, reconheceu que o próprio modelo autônomo é ideológico (STREET, 2013). Dado esse reconhecimento e visando facilitar o processo de como identificar questões ideológicas e políticas que permeiam os múltiplos letramentos situados nos diferentes contextos, ele propôs a adoção de dois conceitos: eventos de letramento (STREET, 2001), com base no conceito já proposto por Heath (1982), e práticas de letramento (STREET, 1984, 2001, 2013).

Considerando o objetivo traçado para este artigo, interessa-me o conceito de práticas de letramento, definido por Street (1984, p.1) como "práticas sociais e concepções de leitura e escrita associadas aos eventos de letramento". Trata-se de um conceito intrinsecamente ligado à visão de letramento defendida no modelo ideológico letramento como prática social, situada, heterogênea, flexível, plural. O reconhecimento dessa pluralidade se evidencia na compreensão das práticas de letramento como algo que se relaciona a diferentes concepções de leitura e escrita. Assim, subjacente a esse conceito está o entendimento de que não existe apenas uma concepção de leitura e de escrita, como acreditam os adeptos ao modelo autônomo de letramento, mas várias concepções, a depender do contexto.

Em publicação posterior, Street (2013) aprimora a definição de práticas, ao afirmar que:

nós trazemos para um evento de letramento conceitos, modelos sociais, relativos ao que é a natureza do evento e o que o fez funcionar e dar-lhe significado. As práticas de letramento, então, se referem ao conceito cultural mais amplo de formas particulares de se pensar sobre e realizar a leitura e a escrita em contextos culturais. (STREET, 2013, p.54-55).

Essas assertivas de Street (2013) evidenciam que a noção de práticas de letramento é abstrata, no sentido de que não são observáveis, como os eventos, mas ligadas a algo mais amplo, situado culturalmente. Relacionam-se a questões que envolvem crenças, valores, atitudes, sentimentos e relações culturais e sociais que subjazem às maneiras pelas quais as pessoas lidam com a leitura e a escrita (STREET, 2013).

O conceito de práticas de letramento é basilar para meu estudo, porque, ao explorar as experiências de leitura descritas e avaliadas pelos participantes, busco observar, com base nas entrevistas realizadas, a que práticas de letramento essas experiências podem estar relacionadas, conforme mostro na subseção a seguir. 
Outro conceito fundamental para minha pesquisa é o da abordagem dos Letramentos Acadêmicos (LEA; STREET, 1998), já referido na introdução deste texto. Em tal abordagem, a leitura, assim como a escrita, é vista como uma prática social e situada, heterogênea, variável, perpassada por questões ideológicas e identitárias. Difere-se, assim, das outras abordagens também identificadas pelos pesquisadores Lea e Street (1998): habilidades de estudo e socialização acadêmica. Na primeira, a leitura é fruto do domínio de um conjunto de habilidades individuais e cognitivas que o leitor transfere ao ler qualquer texto, em quaisquer situações. Já na segunda, a leitura resulta do domínio de um conjunto de variáveis que envolve os modos de usar as práticas de leitura valorizadas nas áreas e disciplinas.

Cabe-me destacar que, na vida diária, essas abordagens não se apresentam de forma "pura" nem homogênea. Como são identificadas a partir da análise daquilo que as pessoas fazem e dizem com/sobre a leitura (e a escrita), é provável que existam, em um mesmo contexto de investigação, formas de agir e falar sobre a leitura (e a escrita) que podem ser associadas a uma abordagem ou a outra.

\title{
3.2 Experiências com a leitura de textos acadêmicos no curso de Pedagogia
}

Ao descreverem e avaliarem como eram suas experiências com a leitura de textos acadêmicos, no curso de Pedagogia, os estudantes apontaram estranhamentos e dúvidas quanto aos modos pelos quais a leitura acontecia na universidade. A seguir, exploro quatro trechos de entrevistas que evidenciam essa minha constatação: dois são relativos às falas de duas concluintes - Yasmim $^{3}$ e Raquel - e os outros dois, de duas calouras - Carla e Mariana. Segue o primeiro trecho:

\begin{abstract}
$P$ (Pesquisadora): Você pode relatar como é que foi: a sua experiência, no primeiro período, quando você se deparou com os textos acadêmicos?

$Y$ (Yasmim): Olha, no início, eu me lembro que: o que era:/ eu tinha uma:, uma estranheza, assim, quanto: (++) à fragmentação, sabe (+). Porque às vezes, quando você recebe o plano de aula, às vezes, tinha, assim (+), um artigo, né? (+). Pra próxima aula, seria um artigo pra ler $(+)$. A professora $(+)$ ia discutir o artigo. Aí:, na outra, às vezes era um capítulo de livro. Aí:, na outra, um prefácio (++) /.... Se lê Paulo Freire, aí:, na outra aula, já era um outro autor /.../. Eh (+), é bem fragmentado. Tende a ser bem fragmentado, assim. (Entrevista, Yasmim, 2015)
\end{abstract}

No trecho exposto, Yasmim cita alguns textos que ela leu no início do curso nomeados de "artigo", "capítulo de livro" e "prefácio" -, caracterizando como "fragmentada" a forma pela qual a leitura desses textos era indicada nas aulas: "às vezes, tinha, assim (+), um artigo, né? (+). Pra próxima aula, seria um artigo pra ler $(+)$. A professora (+) ia discutir o artigo. Aí:, na outra, às vezes era um capítulo de livro. Aí:, na outra, um prefácio (++). I.../ Se lê Paulo Freire, aí:, na outra aula, já era um outro autor". A ideia de "fragmentação" é construída pela estudante a partir do modo pelo qual ela descreve o que acontecia na sequência das aulas: todas as vezes que faz referência a uma aula, por meio da locução adverbial "na outra", cita um texto

\footnotetext{
${ }^{3}$ Todos os nomes dos participantes são fictícios.
} 
diferente - "artigo", "capítulo de livro", "prefácio". A repetição dessa locução adverbial, antecedendo a menção a esses diferentes textos, é uma pista de contextualização que enfatiza a compreensão de Yasmim de que não havia, em sua opinião, uma sequência lógica na escolha dos textos e dos autores a serem lidos, pois, em cada aula, era discutido um texto diferente, escrito por determinado autor, publicado em dado suporte (periódico, livro). Outra pista que reforça essa compreensão da estudante é a repetição da expressão "bem fragmentado" que, assim como o uso do substantivo "fragmentação", também utilizado pela discente, funciona como elemento caracterizador da maneira pela qual a leitura se configurava nas aulas, segundo a aluna. deveria ler:

À semelhança de Yasmim, Raquel estranhou, no início do curso, os textos que

/.../ Eu ficava sempre: assustada, porque: era sempre pedaços de:, de texto. Você não tinha acessol por exemplo (+), era um artigo de um livro. Você ((o aluno)) não tinha acesso ao livro. Era um pedaço do texto. Era o artigo que a gente xerocava do livro. Às vezes, você nem sabia o nome do livro. O professor chegava com aquele trem ((regionalismo mineiro)), e já deixava no xérox ((local onde se reproduzem cópias de material impresso)): "imprime aqui, lê aquele pedaço”. Eu ficava sentindo falta de um contexto. (Entrevista, Raquel, 2015).

No trecho apresentado, Raquel caracteriza o que lia no curso - "pedaços de texto" - e relata como tinha acesso aos textos que deveria ler - "O professor chegava com aquele trem ((regionalismo mineiro)), e já deixava no xérox ((local onde se reproduzem cópias de material impresso)): 'imprime aqui, lê aquele pedaço"”.

A caracterização dos textos lidos a partir da escolha discursiva "pedaços de texto" é esclarecida pela concluinte, quando afirma que "Você ((o aluno)) não tinha acesso/ por exemplo (+), era um artigo de um livro. Você não tinha acesso ao livro. Era um pedaço do texto. Era o artigo que a gente xerocava do livro". Nesse exemplo dado por Raquel, o livro seria o texto completo, enquanto que o artigo seria uma parte dele, um "pedaço de texto". Para ela, os textos indicados para leitura não tinham sentido completo por si mesmos, eram "pedaços de texto", já que o texto completo (o livro) não havia sido disponibilizado pelo professor, segundo afirmou. A escolha discursiva da palavra "trem" reforça a crítica da estudante em relação à forma como tinha acesso aos textos que deveria ler, pois, de acordo com a interpretação mineira, chegar com um trem é uma expressão pejorativa, significando chegar com qualquer coisa, ou seja, o professor pedia aos estudantes que lessem algo que lhes era desconhecido, um "trem". Em virtude dessa situação, ela afirma que, na época do primeiro período do curso, "ficava sentindo falta de um contexto", ou seja, de algo que pudesse situar/justificar os motivos da escolha daqueles "pedaços de texto".

As afirmações feitas por Yasmim e Raquel sugerem possível desconhecimento das relações intertextuais que podem ser estabelecidas entre os diversos textos indicados para leitura, em dada disciplina. Geralmente, as escolhas dos professores são influenciadas por questões relativas à constituição das disciplinas e dos currículos. Os programas das disciplinas, construídos historicamente, preveem o tempo e os espaços curriculares, podendo interferir, assim, nas escolhas e nas decisões feitas pelos professores quanto ao que é mais válido e adequado fazer, conforme a lógica disciplinar.

Além disso, o fato de, em cada aula, ser discutido um texto diferente mostra a diversidade textual presente nas disciplinas, possivelmente sinalizadora de diferentes 
abordagens sobre o mesmo tema, feitas por diferentes autores, cujos textos pertencem a gêneros discursivos variados: "prefácio", "capítulo de livro" e "artigo acadêmico", contribuindo para a intertextualidade nas aulas. Portanto, geralmente, o professor faz a seleção dos textos a serem discutidos nas aulas em função de um planejamento geral elaborado com vistas ao atendimento de objetivos didáticos estipulados. É com base nesse planejamento que ele pode considerar desnecessário indicar a leitura de todos os capítulos de um dado livro ou todos os artigos publicados em um dado periódico; ou, pode considerar produtivo adotar um único livro ou mais de um capítulo de uma mesma obra.

Entretanto, se o objetivo e a função da diversidade textual, nas disciplinas, não são explicitados para os estudantes, e se eles, por si sós, não conseguem significá-los, haverá uma grande probabilidade de caracterizarem como "fragmentada" a sequência dos textos indicados para leitura, como o fez Yasmim, ou ficarem pensando que estão lendo "pedaços de texto", como afirmou Raquel. As escolhas discursivas "fragmentada", "pedaços de texto", juntamente com "fragmentação", "falta de um contexto" e "trem", parecem sugerir essa não explicitação, em sala de aula, das razões que motivaram a seleção dos textos para leitura, as quais poderiam situá-los dentro de um planejamento didático maior que norteia, em geral, as escolhas dos docentes.

A ação de indicar textos para leitura sem explicitar que relações podem ser estabelecidas entre os mesmos está vinculada a uma prática de letramento recorrente no contexto universitário, qual seja: ausência de explicitação das normas e convenções que norteiam a leitura (e a escrita) acadêmica. Parte-se do pressuposto de que os participantes desse contexto já conhecem as práticas letradas nele desenvolvidas, suas características, finalidades e funções - uma compreensão tácita do conhecimento acadêmico (JACOBS, 2005). Entretanto, como a maioria ainda não as conhece, surge o que Lillis (1999) denominou de Prática Institucional do Mistério: as convenções acadêmicas não são transparentes para aqueles que fazem parte da academia professores, estudantes e pesquisadores. A pesquisadora britânica chegou a essa conclusão, depois de ter observado, em uma universidade do Reino Unido, como estudantes não tradicionais ${ }^{4}$ atribuíam sentido à escrita de ensaios. A partir de entrevistas realizadas com eles, Lillis (1999) percebeu que essa prática surge da "tentativa dos estudantes de dar sentido às convenções que subjazem à escrita acadêmica [...], porque a visão que prevalece é que as convenções não são problemáticas e simplesmente são do senso comum"5 (LILLIS, 1999, p. 127).

Os dados explorados na minha pesquisa mostram que a prática do mistério não diz respeito apenas à escrita, mas também à leitura, como evidenciaram as descrições feitas por Yasmim e Raquel, sinalizadoras das dificuldades que sentiram de atribuir sentido ao que liam na universidade. As experiências desfrutadas pelas calouras do curso de Pedagogia parecem ratificar também a prática institucional do mistério quanto à leitura acadêmica, a exemplo das avaliações feitas por Carla e Mariana no tocante aos textos que liam no primeiro período do curso.

Carla faz alguns comentários sobre a natureza dos textos que alguns professores indicavam para leitura:

\footnotetext{
${ }^{4}$ Indivíduos de grupos sociais anteriormente excluídos da educação superior na Grã-Bretanha.

${ }^{5}$ Texto original: "their [of students] attempt to make of the conventions surrounding student academic writing [...] [because] the view prevails that such conventions are unproblematic and simply 'commons sense."”
} 
/.../ E têm professores que: se preocupam também, assim, “ah, eu não vou dar os clássicos porque são muito antigos e a pessoa ((o aluno)) tem dificuldade de ler por causa do:, do tipo de linguagem". E muitas vezes não acontece isso (+), porque:/ pelo menos pra mim, não, sabe. Eu andei pegando uns textos do Durkheim (+) pra ler (+), porque: dois professores falaram sobre Durkheim e nenhum passou o texto original do Durkheim (+), e: não achei: difíceis (+). Eu fiquei bastante incucada assim, sabe, porque: são tantos conceitos, tantas coi:sas, que não é possível que estejam naqueles textos ((dos divulgadores de teoria)) ((tom de riso)) /.....(Entrevista, Carla, 2015)

No trecho exposto, Carla afirma que alguns professores do curso de Pedagogia não indicavam a leitura de textos de autores clássicos, a exemplo de Durkheim - "dois professores falaram sobre Durkheim e nenhum passou o texto original do Durkheim”" -, com o argumento de que "são muito antigos e a pessoa ((o aluno)) tem dificuldade de ler por causa do:, do tipo de linguagem". Ela discorda desse argumento, considerando sua própria experiência: "Eu andei pegando uns textos do Durkheim (+) pra ler (+) /.../ e: não achei: dificeis".

As assertivas "não achei: difíceis", "eu fiquei bastante incucada", "são tantos conceitos, tantas coi:sas, que não é possível que estejam naqueles textos", e o tom de riso pelo qual foram pronunciadas evidenciam a discordância da estudante quanto à não indicação da leitura dos clássicos. Sugerem também que a ausência de indicação desse tipo de leitura significa, para a estudante, uma desvalorização da capacidade dos discentes de ler e entender esses textos, subestimando seu potencial para aprender, pois ela, ao buscar textos produzidos por Durkheim, não sentiu dificuldades em lê-los.

Mariana compartilha com Carla da necessidade de ler textos-fonte:

P (Pesquisadora): E:, pra terminar, que avaliação você faria do semestre, considerando as experiências de escrita e de leitura?

M (Mariana): Assim (2), teve uma aula que uma professora abriu mão de dar um autor direto da fonte, da fonte. O professor falou mesmo pra dar uma versão (+) bem mais simplifica:da de alguém falando sobre ele $(($ autor $))$. Eh $(+)$, por que não enviar, então, o autor como leitura complementar? Quem pudesse, que lesse o autor /.../. É claro, é difícil. São MUItos textos pra ler. Toda matéria, são MUItos textos. É MUIta coisa, sim. MUIta mesmo. Mas a gente tem que ter noção que a gente não pode abrir mão dessa qualiDAde da leitura pra nossa formação (+), por cau:sa das outras coisas, sabe /.../.(Entrevista, Mariana, 2015)

No trecho exposto, Mariana, ao se referir ao que lia no seu curso, menciona o caso de uma professora que indicou a leitura de um texto de divulgador de teoria "versão (+) bem mais simplifica:da de alguém falando sobre ele ((autor))" -, em detrimento do autor da teoria - "abriu mão de dar um autor direto da fonte". A estudante, assim como Carla, se incomoda com a não indicação da leitura de textosfonte, por isso sugere que os professores os indiquem como leitura complementar: "por que não enviar, então, o autor como leitura complementar? Quem pudesse, que lesse o autor". Para ela, não indicá-los pode comprometer a formação dos graduandos, já que considera os textos-fonte como mais qualificáveis: "a gente não pode abrir mão dessa qualiDAde da leitura pra nossa formação”. 
Ambas calouras avaliam negativamente a escolha de alguns professores de não adotarem textos-fonte em determinada disciplina. Embora existam diferenças entre ler um texto-fonte e ler um texto escrito por um divulgador de teoria, a escolha deste em detrimento daquele não se dá, muitas vezes, sem motivos, aleatoriamente, pelo contrário, às vezes, o texto-fonte é de difícil acesso, ou é muito denso e complexo para quem ainda não tem outras leituras, ou, ainda, está escrito em uma língua estrangeira. Em virtude disso, e de outras razões, inclusive de natureza disciplinar e curricular, como mencionei anteriormente, o professor pode preferir indicar a leitura de textos de divulgadores de teoria.

Os questionamentos das calouras apontam, assim, para a prática institucional do mistério (LILLIS, 1999), pois podem ter surgido devido ao fato de, possivelmente, não terem sido esclarecidas quanto aos por quês das escolhas feitas pelos professores. A ausência de explicitação do modo como a leitura acontece, no âmbito acadêmico, pode dificultar o processo de apropriação das práticas letradas, porque o fato de estar lidando com elas não garante entendê-las, nem significá-las. Esse mistério está presente nos contextos acadêmicos, embora com nuances diferenciados, dado o pressuposto de que as ações docentes e as práticas acadêmicas são autoexplicativas, transparentes, compreensíveis para todos. Como não o são, surgem tensões entre as expectativas dos professores e as dos alunos, não só em relação à escrita (LEA; STREET, 1998), mas também à leitura, visto que ambas são práticas sociais e situadas, logo, variam conforme as áreas e disciplinas em que aparecem.

\section{Palavras finais}

Neste artigo, objetivei examinar experiências de estudantes do curso de Pedagogia, de uma universidade federal brasileira, com a leitura de textos acadêmicos. Para tal, fundamentada na compreensão de leitura enquanto prática social, entrevistei calouros e concluintes desse curso. Ao explorar descrições e avaliações feitas por eles sobre suas relações com a leitura acadêmica, mostrei que parecem revelar suas dificuldades de entender a lógica da academia: a diversidade de textos indicados para leitura não significa, necessariamente, uma "fragmentação" ou são "pedaços de textos", mas sua escolha está ligada, em geral, ao que rege a organização das disciplinas e dos currículos; a não indicação de textos-fonte nem sempre quer dizer que o professor está subestimando o estudante ou não está comprometido com uma formação de qualidade, mas pode ser devido à dificuldade de ter acesso a esses textos ou porque entende ser mais viável primeiro indicar a leitura de um divulgador da teoria para depois indicar o próprio autor.

Essas falas dos participantes da pesquisa sugerem que, no caso do contexto investigado, parece não haver explicitações quanto às práticas de leitura acadêmica. É como se a leitura de textos acadêmicos já fosse conhecida dos discentes, logo, não seria necessário ensiná-la. Esse pressuposto está em consonância com os princípios da abordagem habilidade de estudo (LEA; STREET, 1998): a leitura, assim como a escrita, é uma habilidade individual e cognitiva que, uma vez aprendida, pode ser, supostamente, mobilizada em quaisquer contextos. Está em consonância também com a crença de que, quando o indivíduo aprende a ler, ele aprende de uma vez por todas, então, não há necessidade de lhe ensinar algo relativo à leitura, quando ele chegar à universidade. Está em consonância, ainda, com a compreensão de que a natureza dos conhecimentos acadêmicos é tácita (JACOBS, 2005) - a aprendizagem na academia 
ocorre implicitamente, pois parte-se do pressuposto de que os conhecimentos são transparentes seja para os estudantes, seja para os professores, seja para os pesquisadores.

Em virtude desse contexto de suposta transparência, a proposta de Wingate (2015), de que a leitura acadêmica seja ensinada para os universitários, como também defende Górska-Fernando (2016), é produtiva e bastante relevante. No entanto, acrescento que esse ensino não deveria se restringir a explicitar $o$ que acontece com a leitura acadêmica, mas, sobretudo, por que acontece de determinada forma, contribuindo para o desenvolvimento, nos estudantes, de uma postura reflexiva frente às práticas letradas com as quais têm contato na academia, conforme as lentes da abordagem dos Letramentos Acadêmicos (LEA; STREET, 1998) nos permitem fazê-lo.

\section{Referências}

BOGDAN, R. C.; BIKLEN, S. K. Investigação qualitativa em educação. Tradução Maria João Alvarez, Sara Bahia dos Santos e Telmo Mourinho Baptista. Porto: Porto Editora, 1994. 337p.

CASTANHEIRA, M. L.; CARVALHO, G. T.; STREET, B. Navigation across academic contexts: Campo and Angolan students in a Brazilian university. In: GREEN, J. L.; BAKER, W. D. Pedagogies - an Internacional Journal, Routledge, v. 10, n. 1, p. 70-85, Jan./Mar. 2015.

FERNÁNDEZ, G. M. E.; CARLINO, P. En qué se diferencian las practices de lecture y escritura de la Universidad y las de la escuela secundaria? Lectura y Vida, Buenos Aires, v. 31, n. 3, p.6-19, Sept. 2010.

FIAD, R. S. A escrita na universidade. Revista da ABRALIN, v. Eletrônico, n. Especial, p. 357-369, 2011.

Reescrita, Dialogismo e Etnografia. Linguagem em (Dis)curso, Tubarão, SC, v. 13, n. 3, p. 463-480, set./dez. 2013.

(Org.). Letramentos Acadêmicos: contextos, práticas e percepções. São Paulo: Pedro \& João Editores, 2016. 357p.

FISCHER, A. Sentidos situados em eventos de letramento na esfera acadêmica. Revista do Centro de Educação, Santa Maria, Rio Grande do Sul, v. 35, n. 2, p. 215-228, maioagosto 2010. Disponível em:< http://www.ufsm.br/revistaeducacao>. Acesso em: 14 de set. 2017.

GEE, J. P. Social linguistics and literacies: ideology in Discourses. 2. ed. London/ Philadelphia: The Farmer Press, 1996 [1990]. 203p.

GÓRSKA-FERNANDO, W. Ways with writing - an ethnographically oriented study of student writing support in higher education in the UK. 2016, 360f. Tese (Doutorado em Filosofia) - King's College London, Reino Unido. 
GUMPERZ, J. Convenções de contextualização. In: RIBEIRO, B. T.; GARCEZ, P. M. (Orgs.). Tradução de José Luiz Meurer e Viviane Heberle. Sociolinguística Interacional. São Paulo: Edições Loyola, 2002 [1982]. p. 149-182.

HEATH, S. B. Protean shapes in literacy events: ever-shifting oral and literate traditions. In: TANNEN, D. (Org.). Spoken and written language: exploring orality and literacy. Norwood, N.J.: Ablex, 1982. p. 91-117.

IVANIC, R. It is for interpersonal: discoursal construction of writer identities and the teaching of writing. Linguistics and Education, v. 6, n. 1, p. 3-15, 1994.

JACOBS, C. On being an insider on the outside: new spaces for integrating academic literacies. Teaching in Higher Education, v. 10, n. 4, p. 475-486, Oct. 2005.

LEA, M. R; STREET, B. Student writing in higher education: an academic literacies approach. Studies in Higher Education, v. 23, n. 2, p. 157-172, Jun. 1998.

LILLIS, T. M. Whose 'Common Sense'? Essayist literacy and the institutional practice of mystery. In: JONES, C.; TURNER, J.; STREET, B. (Orgs.). Students writing in the university: cultural and epistemological issues. Amsterdam: John Benjamins, 1999. p. 127-140.

MARCUSCHI, A. L. A. Análise da conversação. São Paulo: Ática, 1991. p. 10-13.

MARINHO, M. A escrita nas práticas de letramento acadêmico. Revista Brasileira de Linguística Aplicada, Belo Horizonte, v. 10, n. 2, p. 363-386, 2010.

MITCHEL, J. C. Case studies. In: ELLEN, R. F. Ethnographic research: a guide to general conduct. London, FL: Academic Press Inc., 1984. p. 237-241.

PATAI, D. Brazilian women speak - contemporary life. Rutgers: The State University, 1988. p. 1-38.

ROBINSON-PANT, A; STREET, B. 'Students' and tutors' understanding of 'new' academic literacy practices'. In: University writing: Selves and Texts in Academic Societies. Montserrat Castelló; Christiane Donahue (Eds.). Emerald Press: UK, 2012. p.71-92.

SPRADLEY, J.P. The ethnographic interview. New York: Holt, Rinehart, \& Winston, 1979. 256p.

STREET, B. Literacy in Theory and Practice. Cambridge: Cambridge University Press, 1984. 256p.

(Org.). Introduction: the new literacy Studies. In: Cross Cultural Approaches to Literacy. Cambridge: Cambridge University Press, 1993.

Literacy events and literacy practices: theory and practice in the New Literacy Studies. In: MARTIN-JONES, M.; JONES, K. E. (Orgs.). Multilingual Literacy: 
reading and writing different worlds. Amsterdã/Filadélfia: John Benjamins, 2001, p. 1729.

What's "New" in New Literacy Studies? Critical approaches to literacy in theory and practice. Current Issues in Comparative Education, Teachers College, Columbia, University, v. 5, n. 2, p. 77-91, May. 2003.

Políticas e práticas de letramento na Inglaterra: uma perspectiva de letramentos sociais como base para uma comparação com o Brasil. Cad. CEDES, Campinas, v.33, n. 89, p. 51-71, jan./abril 2013. Disponível em: < http://dx.doi.org/10.1590/S010132622013000100004>. Acesso em: 20 jun. 2017.

WINGATE, U. Academic literacy and student diversity: the case for inclusive practice. United Kingdom: Multilingual Matters, 2015. 208 p.

Recebido em 15 de fevereiro de 2019

Aceito em 25 de maio de 2019 